\title{
Analysis of the Trends of Ideological and Political Work of College Counselors under the Perspective of Strengths
}

\author{
Yujun Luo \\ School of Marxism, Wuhan University of Technology, Wuhan 430070, China. \\ 924327993@qq.com
}

\begin{abstract}
With the problem of higher education talent quality of bourgeois deepening and specialization of counselors' professionalization process of development, College counselors work more and more get the attention of the society from all walks of life. Strength perspective is accepted by social workers at home and abroad and widely used in theory. More and more scholars hope that through the perspectives of strength can change the style of ideological and political education work of university counselors, improve college counselors work methods of work, enhance the level of its education work and improve the quality of talent cultivation status. This paper combed the trend of the research on Ideological and Political Work of College Counselors under the perspective of strengths, hoping to make scholars who research on the theory have a comprehensive understanding, and cause the attention of more scholars and research.
\end{abstract}

Keywords: Strengths perspective; college counselors; ideological and political education.

\section{优势视角下的高校辅导员思政工作研究趋势分析初探}

\author{
骆昱君 \\ 武汉理工大学 马克思主义学院, 武汉 中国
}

摘 要: 随着高等教育人才质量平庸化的问题不断加深以及辅导员专业化职业化进程的不断发 展, 高校辅导员工作越来越受到社会各界的关注, 优势视角是被国内外的社会工作者接受并 广泛运用的理论, 越来越多的学者希望通过优势视角的运用, 转变高校辅导员思想政治教育 工作的一贯风格, 改善高校辅导员工作的工作方法, 提升其思政工作水平, 改善人才质量培 养现状。本文梳理了优势视角下高校辅导员思政工作这一研究的趋势, 希望使学者们对这一 理论研究有一个全面的理解, 并引起更多学者的重视和研究。

关键词：优势视角；高校辅导员；思想政治教育

\section{1. 前言}

教育的本质在于使个体实现自身潜能，成为合格的国家公民; 卓越教育的本质则在于使 个体追求高远的目标和非凡的能力，成为全面建成小康社会、建设社会主义事业坚实的后继 力量。大学生肩负国家的未来和希望, 目前我国高等教育由精英化向普及化转换的道路上成 绩可喜, 但随着大学生人口猛增而来的大学生质量平庸化是需要我国高等教育实践回应的一 个现实问题。

随着高等教育人才质量平庸化的问题不断加深以及辅导员专业化职业化进程的不断发 展, 高校辅导员工作越来越受到社会各界的关注, 辅导员由于其与学生关系的特殊性, 对学 生成才的培养有着天然优势，然而目前其在高校人才质量培养上贡献不足使其存在的合理性 也越来越受到社会各界的质疑。优势视角是被国内外的社会工作者接受并广泛运用的理论, 我们不能保证仅凭这一视角就能够解决人才培养质量问题, 但是通过优势视角的运用, 转变 高校辅导员思想政治教育工作的一贯风格, 改善高校辅导员工作的工作方法, 提升其思政工 作水平，对于改善人才培养质量将具有一定的理论和现实意义。 


\section{2. 研究的趋势分析}

\section{1. 国内外研究}

优势视角的概念是美国堪萨斯大学的丹尼斯 - 萨利贝教授在《优势视角:社会工作实践的 新模式》一书中最早提出来的。他第一次将与社会工作传统的重点关注个体的问题、病态、 偏差的问题视角完全相反的，一种全新的重点关注个体的优势、潜能和成绩的优势视角引入 了社会工作。2004年由学者李亚文、杜立婕翻译, 华东理工大学出版社出版的这本书中, 萨 利贝教授比较全面的介绍了优势视角理论的理念及运用原则。社会工作的优势视角不同意将 服务对象看做是问题，认为给案主贴上各种各样的问题标签将损害服务对象自我及周围人对 案主的正确认知, 这种损害将会融入他们的自我认同及信心。他认为优势视角是对问题视角 的一次全新的突破, 在运用优势视角理论时应注意到: 人人、家家、事事都有优势; 案主遇到 的困难、危机具有伤害性, 但它们也可能是挑战和机遇; 创建合作性关系, 能最有效服务于案主; 案主的任何环境都充满资源。Saleebey教授的这些理论构成了优势视角理论的基础。

国内关于优势视角的理论研究兴起于较近2006年，专门针对优势视角的大多为论文，论 著很少, 代表论著作为李亚文、杜立婕翻译Saleebey的译著《优势视角:社会工作实践的新模 式》及台湾学者宋丽玉、施教裕教授《优势观点: 社会工作理论与实务》, 其余大多作为社会 工作的重要范畴被在社会工作学的书籍中提及。

尽管关于优势视角的专门的理论研究并不多, 但优势视角作为一种具有很强的实用功能 的理论被广泛运用于如经济学、管理学、教育学等学科领域以及实际问题的解决当中。

2.2. 优势视角在教育中的运用

教育的对象的发展往往是不均衡的，我们的教育应当提倡 “有教无类、因材施教”，“后 进生” “绩差生” “问题生” 尽管暂时表现得不尽人意, 但是他们的潜能与资源是无限的, 因而将优势视角运用于教育领域意义重大。

而近年来优势视角在我国教育领域当中的运用发展亦十分明显, 在中职生教育, 高校教 育, 留守儿童教育、新型农民教育、残疾人教育等方面均有所发展。如郭宝仙（2013）综述 了近50年来国外的优势视角替代问题视角的趋势, 并且希望重视优势视角的基础理论的学习 和研究, 将发扬优势作为教育的重点, 努力构建具有本土特色的评价工具。宋芗（2008）从 本质上比较”优势视角”与“问题视角”的区别, 并阐述了残疾未成年犯生理心理上的特点以及 他们的特殊优势, 认为将“优势视角”理论应用在在残疾未成年犯”寓教于审“工作中将起到重 要作用。李晓燕 (2014) 以一名高功能自闭症幼儿的语言运用为例进行分析发现, 同伴型优势 视角对于自闭儿个案的语用交互能对幼儿有较好的支持作用。武迪、张肖蒙、曹自爱 (2014) 在深入阐释留守儿童现状的基础上, 希望通过优势视角改善留守儿童以及留守儿童工作的现 状。鞠金金（2012）指出当前我国高校生命教育理论和实践缺位, 基于优势视角对八零九零后 大学生进行生命教育有助于尊重大学生个体, 挖掘他们的潜能, 培育其乐观向上的生命态度。

2.3. 优势理论在高校思想政治教育领域的运用

高校思想政治教育的对象为在校大学生, 大学生正处于人生的青年阶段, 应是最朝气蓬 勃、锐意进取的阶段, 然而现实情况是许多大学生在面临人生的充电阶段却选择了停滞甚至 倒退, 这与大学生个人的个性、家庭背景等因素等融入了其行为机制有关, 也与其所处的环 境以及是否受到良好的引导相关, 因此高校思想政治教育对大学生的引导责任义不容辞, 大 学生的思想处于成熟与成长并行的时期, 思想政治教育工作在这一群体上是否可以达到实效 是学者们十分关注的问题。

优势视角在这一问题上显然具有一定实效, 高双双、钟坚石（2014）将大学思想政治教 育的主要服务对象界定为大学生弱势群体, 提倡运用优势视角帮助他们发掘自身优势充分调 动资源, 提升主观能动性, 令其走出低谷, 在过程中培养起弱势大学生解决危机的能力, 以 期真正意义上提升高校思想政治教育实效。韩娜，王永顺（2014）认为优势视角不同以往的 概念, 特别是抗逆力原则和外展工作原则等为更新高校思想政治教育理念与教育方式提供了 新视角。许黄漟 (2015) 认为高校思想政治教育的核心任务就是大学生成长成才, 将社会工作 
中的优势视角引入大学生工作的案例中去, 寻找二者有效结合的路径, 不失为高校思政教育 工作的新路子。章丽娟（2013）阐述了优势视角可以在高职院校在对问题学生做工作中起到 规避原有的缺陷, 促进学生自我教育的作用。刘翠英 (2015) 深入探讨了运用优势视角在班 内开展积极心态培养的七大教育策略与步骤。

2.4. 优势理论在辅导员工作中的运用

直接将优势理论与高校辅导员工作相结合的研究目前来说少之又少, 在武汉理工大学电 子图书馆中搜索, 只有 2013 年孙文霞发表在长春工业大学学报上的《优势视角下高校辅导员 工作的角色转换》、2015年邵明颖发表在哈尔滨职业技术学院学报上的《优势视角理论下高 校辅导员队伍的专业化、职业化思考》两篇相关期刊以及2013年华中农业大学的陈君发表的 硕士论文《优势视角下高校辅导员能力提升社会工作介入研究: 以温州科技职业学院为例》。 而这其中, 只有 2013 年孙文霞发表在长春工业大学学报上的《优势视角下高校辅导员工作的 角色转换》是以辅导员工作内容为对象将优势视角运用于辅导员工作中, 而另外两篇均是以 辅导员为对象, 将优势视角运用于辅导员自身提升。孙文霞 (2013) 认为在优势视角下辅导 员的角色转换主要是三个方面: 即引导者, 潜能和优势的发掘者和资源的联系和提供者。相 对于其他视角来说, 在优势视角下辅导员应做好角色的转换, 从而更好地为大学生成长成才 服务。

可知将优势视角运用于辅导员学生思想政治教育工作的研究, 就目前来说十分缺乏, 就 研究趋势来说, 将会有一定的研究者继续对这一领域尝试进行探索, 丰富相关理论, 查缺补 漏, 完善这方面的研究。

\section{3. 研究意义}

理论层面, 随着高等教育人才质量平庸化的问题不断加深以及辅导员专业化职业化进程 的不断发展, 高校辅导员工作已经受到社会各界的越来越多的关注, 不少专家学者为高校辅 导员相关理论实践形成做出了相当的努力, 甚至有学者提出辟 “辅导员学” 为专门的学科, 以提升研究针对性并促进思想政治教育的学科发展。而借鉴各学科理论丰富辅导员思想政治 教育理论及实务也成为越来越多思政学者和专家的关注热点。以辅导员思想政治教育为切入 点, 引入社会工作中的优势视角, 除了是对社工理论的实践检验, 有助于丰富思想政治教育 理论的同时, 扩展辅导员工作实务理论, 为完善 “辅导员学” 体系提供借鉴。同时也从实践 探索层面上丰富了优势理论。

现实层面, 在我国高校扩招已经到了第 17 个年头, 我国高等教育已经跨过了精英化过渡 至大众化的门槛, 正向着普及化迈进的道路上, 高校人才培养质量已经成为摆在国家、高校 面前迫切需要解决、刻不容缓的社会问题。辅导员由于其与学生关系的特殊性, 对学生成才 的培养有着天然优势, 然而目前其在高校人才质量培养上贡献不足使其存在的合理性也越来 越受到社会各界的质疑。优势视角是被国内外的社会工作者接受并广泛运用的理论, 探索运 用各种科学理论改进辅导员工作, 千方百计提升辅导员思想政治教育有效性, 提升高校人才 培养质量, 同时为辅导员工作形成系统提供参考, 是其的现实意义所在。

\section{4. 现有研究的贡献与不足}

总体来说, 现有的研究对优势视角在各个领域的应用进行了有益探索, 将优势视角的实 务功能在中国本土的环境下得到进一步发挥。就优势视角在高校辅导员工作中的运用来说, 优势视角在高校辅导员工作中已经有了一定的理论探索, 对于优势视角在高校辅导员工作中 的使用作用、使用原则、辅导策略、工作路径等方向都做了理论上的思考与总结, 为优势视 角在高校辅导员工作中的运用提供了借鉴。

但由于研究发展时间尚短, 现有研究整体上存在体系不完整、理论水平尚浅等问题。具 体来说现有的研究也存在一些不足: 首先, 现有的研究大多数关注优势视角作用下的客体对 
象, 比如高校的弱势学生群体, 针对某一特定客体进行的优势理论方法对其作用的研究, 而 没有从宏观的思想政治教育方法的层面探讨优势理论的运用; 其次, 优势视角在高校辅导员 工作中的实际运用情况上, 仍然停留在理论探索阶段, 相关的实证研究薄弱, 对于优势视角 在现有辅导员工作中的接受程度如何、使用状况如何尚不得而知, 也不能有信服力地说明运 用优势视角和非优势视角下的辅导员工作产生的区别。再次，在思想政治教育工作的具体运 用中，辅导员是否运用了优势视角的工作技巧难以被界定。

\section{5. 建议与反思}

2012年教育部出台《关于全面提高高等教育质量的若干意见》，2013年教育部党组印发 《普通高等学校辅导员培训规划（2013-2017年）》，明确提出要实现 “到2017年，基本形成 适应高等教育发展需要、符合辅导员成长成才规律、规范科学的培训机制, 基本构建起内容 完善、形式多样、科学合理的培训体系, 为全面提高辅导员队伍服务高等教育质量提升和高 校学生全面发展的能力奠定坚实基础” 的目标。2014年教育部印发《高等学校辅导员职业能 力标准 (暂行) 》的通知, 要求各地教育部门、高等学校要把贯彻落实《能力标准》作为加强 高校辅导员队伍建设的重要任务和举措, 努力将高校辅导员队伍建设提升到新水平。

在国家大力发展辅导员队伍专业化、职业化政策的导向下，对于辅导员工作的专业性研 究引起了学界的相当重视, 甚至已经有学者提出将 “辅导员工作学” 作为单独的科学进行研 究并对其作出了相关理论的梳理形成了博士论文以提升辅导员工作的科学性、实效性, 这是 本研究发展的外部诱因及条件。而目前辅导员工作专业研究的不足, 辅导员专业化、职业化 的程度不能满足国家、社会、高校、学生对于辅导员这一职业的要求等现实因素将成为研究 发展的内部因素。在内外因素的作用下, 关于提升高校辅导员的思想政治工作或者学生管理 工作水平的各类研究, 必将得到各界的研究与发展。

优势视角首提于社会工作学, 而后又在积极心理学领域有所发展, 因其关注人的内在优 势和资源的核心内涵在面对弱势群体以及弱势心理上的积极作用, 使得其运用领域广泛且富 有成效, 尤其在教育领域, 以往关注学生问题、偏差、弱点的问题视角将学生看做是教育需 要改造的对象, 忽视了学生的主体性的发挥, 优势视角下的教育工作摈弃对问题的负向意识, 注重学生内在精神力的正向成长, 对于学生潜能的发挥、自主能力的培养有着重要的作用。 近年来越来越多的学者将这一理论运用于高校思想政治教育领域, 也说明了这一理论在这一 领域的研究受到越来越多的重视。优势视角不仅是一种理论视角, 更是一种积极健康的蕴含 智慧思维模式，将其普遍运用于高校思想政治教育工作对于大学生和高校辅导员对我国的高 等教育发展将起积极的作用, 在辅导员工作学中也应占有一席之地。

\section{References}

[1]. Lijie Du. Strength perspective: the new mode of social work practice [J]. Journal of east China University of science and technology (social science edition). 2007.03

[2]. Baoxian Guo. Study of strength Perspective abroad reviewed [J]. Foreign education research. 2013.12

[3]. Ying Song. Perspective of "strength" theory in the application of "able to" review work, in the perspective of the disabled juvenile delinquents [J]. Juvenile crime problem.2008.03

[4]. Xiaoyan Li. Partner type strength perspective: fusion education under the background of autism children's pragmatic interaction support strategy exploration [J] Journal of Inner Mongolia normal university (education science edition).2014.04.

[5]. Xin Ju. Life education of colleges and universities under the perspective of strength [J]. Journal of Changchun University of technology (higher education research). 2012.04. 
[6]. Shuangshuang Gao, Jianshi Zhong. Strength perspective: the new ideas of ideological and political education college students vulnerable groups [J]. Wit. 2014.08

[7]. Na Han, Yongshun Wang. Strength perspective innovation ideological and political education idea and the method of thinking [J]. Journal of Inner Mongolia normal university (education science edition). 2014.01

[8]. Xiaobo Wei. Strength perspective: consider a new perspective of ideological and political education actual effect [J]. Journal of Guiyang College (social science edition). 2012.04

[9]. Huangying Xu. Under the perspective of " strength " ideological and political education work new ideas - asain to college students grow up trouble case analysis [J]. Journal of Hubei correspondence university. 2015.04.

[10]. Lijuan Zhang. Strength perspective problems in higher vocational colleges' students' education and transformation [J]. Jiangsu education research. 2013.27.

[11]. Cuiying Liu. Strength perspective of college students' positive emotional education to explore [J]. Journal of Shandong institute of agricultural engineering. 2015.09. 